\title{
KELAYAKAN PUZZLE SEBAGAI ALAT BANTU GURU DALAM UPAYA PENCEGAHAN KEKERASAN SEKSUAL PADA SISWI SLB-C
}

\author{
Nikita Dwi Mulyaningsih, Mury Ririanty, Erwin Nur Rif'ah \\ Fakultas Kesehatan Masyarakat Universitas Jember
}

*Correspondence: nikitadewi117@gmail.com

Dikirim 25 Oktober 2019; Diterima 27 November 2019; Dipublikasi Februari 2020

\begin{abstract}
Intellectual disabilities was people who have a level of intelligence so low (below normal) that they needed help in carrying out activities. People with intellectual disabilities can stricked sexual violence because of the stigma about disabilities are asexual creatures, especially intellectual disabilities. Therefore, the community restricted the access of health information, especially sexual matters. Besides that, there was several obstacles in conveying health information to people with intellectual disabilities due to the limitations of mental retardation understanding the contens. This is also supported by the lack of media that used to delivery a material to intellectual disabilities people. The purpose of this reasearch is to produce puzzle that can protect people with intellectual disabilities from sexual violence. Research and development with qualitative approach . Using interview, document study and observation methods. The research subjects consisted of eleven people consisting of six teachers of SLB-C TPA Jember, one Headmaster of SLB-C TPA Jember, three psychologist of Garwita Institute and one media expert. Data collection tools are interview guides, observation guides, handpones and stationery. The knowledge about sexual violence and puberty of most informants was still lacking.The informans agreed that girls with intellectual disabilities have problem with their puberty period and sexual violence. The teachers always give a education about puberty and how to protect theirself from sexual violence. The informans also agreed that girls with intellectual disabilities need a puzzle that have message edutaion about puberty and sexual violence.
\end{abstract}

Keywords: Intellectual disabilities, media, Sexual violence, Puzzle.

\section{PENDAHULUAN}

Disabilitas adalah setiap orang yang mengalami keterbatasan fisik, intelektual, mental, dan atau sensoris dalam jangka waktu lama dalam berinteraksi dengan lingkungan dapat mengalami hambatan dan kesulitan untuk berpartisipasi secara penuh dan efektif dengan warga negara lainnya berdasarkan kesamaan hak. Salah satu jenis disabilitas adalah disabilitas mental yang biasa disebut tunagrahita. Berdasarkan data Kementrian Kesehatan tahun 2014 didapatkan bahwa sebanyak 984 ribu penduduk Jawa Timur adalah penyandang disabilitas dan 213 ribu diantaranya termasuk pada tipe penyandang disabilitas intelektual. Data yang terdapat pada Dinas Sosial Kabupaten Jember tahun 2016 menunjukkan bahwa dari 31 kecamatan yang ada di wilayah Kabupaten Jember untuk anak penyandang tunagrahita berjumlah 401 anak. Jumlah siswa di SLB C Jember adalah 93 anak dan kebanyakan dengan kategori tunagrahita ringan.

Penyandang disabilitas termasuk tunagrahita merupakan kaum yang rentan, sehingga penting bagi kita untuk menaruh perhatian khusus bagi mereka(1). Berdasarkan laporan Catatan Tahunan (CATAHU) Komnas Perempuan tahun 2012 menyatakan bahwa di Indonesia terdapat 29 kasus kekerasan terhadap perempuan disabilitas yang ditangani oleh lembaga tersebut. Pada tahun 2016, Catatan Tahunan (CATAHU) menyatakan bahwa kekerasan seksual pada perempuan disabilitas sebesar 93\% (57 dari 61 kasus) dan korbannya didominasi oleh tunagrahita atau penyandang disabilitas mental sebesar 28 kasus serta 1 kasus tunagrahita dan 
tunanetra(2). Berdasarkan data dari POLRES Kabupaten Jember pada Tahun 2019 per Maret didapatkan bahwa terdapat satu kasus kekerasan seksual pada perempuan penyandang disabilitas yaitu tunagrahita.

Kekerasan seksual pada kaum disabilitas terjadi dikarenakan kepercayaan budaya dan sosial juga membatasi seksualitas penyandang disabilitas khususnya tunagrahita serta membatasi akses akan informasi kesehatan terutama masalah

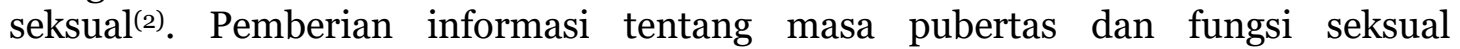
perempuan disabilitas saat remaja merupakan sesuatu yang tidak penting sehingga perempuan penyandang disabilitas sama sekali tidak mengetahui penyebab dan akibat dari perubahan tubuhnya(3). Selain akses terhadap informasi kesehatan yang dibatasi, terdapat kendala yang dihadapi fasilitator atau guru SLB dalam memberikan pendidikan kesehatan terutama kesehatan reproduksi dan pendidikan seksual yaitu tidak semua guru sudah mendapatkan pelatihan tentang kesehatan reproduksi, masih merasa sungkan atau tabu untuk memberikan pendidikan kesehatan reproduksi apalagi jika berbeda jenis kelaminnya dengan guru tersebut. Selain itu, keterbatasan dari penyandang tunagrahita dalam memahami materi dan konsep yang sifatnya abstrak, mudah merasa jenuh ketika proses pembelajaran, susah berinteraksi sosial, memiliki keterbatasan dalam memahami pembelajaran akademik $^{(3)}$. Oleh karena itu, penggunaan media dirasa penting dikarenakan anak tunagrahita sangat sulit untuk memahami bacaan atau tulisan(4).

Berdasarkan penjelasan tersebut, peneliti ingin menggunakan penelitian research and development dengan pendekatan kualitatif. Penelitian ini digunakan untukmenghasilkan media puzzle sebagai alat bantu guru dalam upaya pencegahan kekerasan seksual bagi remaja perempuan tunagrahita. Peneliti menggunakan model $P$ Process dalam perencanaan dan pengembanganmedia pendidikan kesehatan. Hasil penelitian didapatkan dari hasil melakukan tahap analisis situasi untuk mengetahui karakter sasaran serta hasil analisis desain strategis yang dilakukan dengan mewawancari ahli media dan psikolog(5).

\section{METODE PENELITIAN}

Jenis penelitian yaitu penelitian research and development denga pendekatan kualitatif. Pengumpulan data dilakukan dengan teknik wawancara, observasional dan dokumentasi. Subjek penelitian terdiri dari enam orang guru SLB-C TPA Kab. Jember, satu orang Kepala Sekolah SLB-C TPA Kab. Jember, tiga orang psikolog dari Garwita Institute dan satu orang ahli media dari FIB UNEJ. Alat yang digunakan yaitu panduan wawancara, panduan observasi, smartphone sebagai alat perekam dan juga alat tulis. Analisis data dilakukan dengan cara pengumpulan data mentah, kemudian transkip wawancara, membuat koding dan penyimpulan dalam bentuk narasi dan di interpretasikan dan disesuaikan dengan teori yang telah ada dari peneliti terdahulu.

\section{HASIL DAN PEMBAHASAN}

Analisis merupakan tahapan awal ketika melakukan pengembangan terhadap program komunikasi yang efektif yang berguna untuk melihat karakteristik masalah kesehatan beserta hambatan terhadap perubahan perilaku(6). Pada tahapan analisis audiens/ komunikasi dilaksanakan dengan melakukan penelitian formatif terhadap audiens untuk melihat pengetahuan, sikap, keterampilan, jaringan sosial, kebutuhan, aspirasi, dan tingkat self-efficacy mereka yang memengaruhi perilaku mereka(5). Pada penelitian ini peneliti ingin melihat tingkat pengetahuan, sikap, tindakan dan kebutuhan audiens akan media komunikasi yang dirancang peneliti dengan menggunakan enam orang informan penelitian.

Pengetahuan merupakan hasil tahu seseorang terhadap suatu benda/objek yang didapatkan melalui alat indera seperti mata, telinga, hidung dan lain sebagainya(7). Sebagian audiens menyimpulkan pubertas sebagai peralihan dari masa anak-anak kepada masa remaja maupun dewasa. Istilah pubertas digunakan untuk menyatakan adanya perubahan biologis baik dalam segi bentuk maupun fisiologisnya yang terjadi dengan cepat dimulai dari masa anak-anak menuju ke masa dewasa, terutama perubahan pada alat reproduksinya(8). Sebagian besar audiens menyatakan bahwa menstruasi merupakan tanda perempuan mengalami masa pubertas, sebagian sisanya menyatakan bahwa tanda pubertas adalah menyukai 
lawan jenis, payudara dan pinggul membesar, tumbuh rambut ketiak dan kemaluan serta cenderung lebih emosional.

Pada aspek pengetahuan audiens tentang kekerasan seksual, sebagian audiens memahami kekerasan seksual merupakan tindakan pemaksaan aktivitas seksual. Kekerasan seksual juga merupakan segala tindakan yang mengarah pada segala bentuk paksaan atau mengancam untuk melakukan hubungan seksual, melakukan penyiksaan atau bertindak sadis serta meninggalkan seseorang setelah melakukan hubungan seksual. Tindakan yang tergolong pada tindak kekerasan seksual yaitu memegang wajah, membuka rok perempuan, memegang area sensitif perempuan, pemerkosaan, pelecehan seksual, pencabulan serta pedofil. Selain itu tindakan yang tergolong tindak kekerasan seksual menurut Sugikojanto, 2014 adalah mempertontonkan hal-hal pornografi kepada seseorang baik dalam bentuk situs, gambar, film ataupun bacaan, aktivitas seksual kepada seseorang misalkan hubungan seksual mempertontonkan alat kelamin kepada seseorang, berhubungan seksual kepada seseorang dengan paksaan, meraba-raba atau memainkan organ vital seseorang, mengintip dan memata-matai seseorang ketika mandi, memaksa seseorang meraba-raba alat kelamin pelaku, menyebarkan potret seseorang dalam keadaan telanjang.

Salah satu upaya pencegahan kekerasan seksual adalah pemberian pendidikan seksual. Pendidikan seksual perlu diperkenalkan kepada anak-anak bahkan pada anak usia dini(9). Selain itu, pendidikan seksual juga dilakukan dengan mengajarkan tentang empat anggota tubuh yang tidak boleh disentuh oleh orang lain kecuali oleh orang yang sangat dekat dengan anak misalnya ayah atau ibu(10). Hal seperti ini juga dapat diajarkan kepada remaja tunagrahita mengingat penyandang tunagrahita merupakan kaum yang rentan terhadap kekerasan seksual. Namun, hanya sebagian kecil audiens yang mengetahui tentang bagian tubuh yang tidak boleh disentuh serta dapat menyebutkan bagian tubuh tadi dengan benar dan informasi tersebut didapatkan dari melihat video yang disebarkan seseorang di whatsapp messenger maupun sosialisasi di sekolah. Bagian tubuh yang tidak boleh disentuh kecuali atas izin orang tua adalah mulut, dada, penis atau vagina dan pantat. Bagian tubuh tadi merupakan area pribadi sehingga jika terdapat orang asing yang berusaha untuk menyentuh maka anak diharuskan untuk mengatakan tidak atau berteriak (10).

Sikap merupakan respon tertutup seseorang terhadap suatu objek tertentu maupun stimulus yang melibatkan aspek pendapat dan emosi dari orang yang bersangkutan. Sikap adalah suatu kumpulan gejala yang dihasilkan dari respon terhadap stimulus yang melibatkan perasaan, perhatian, pikiran dan gejala kejiwaan lainnya(7). Sebagian besar audiens menyatakan setuju jika remaja putri tunagrahita memiliki masalah terkait dengan masa pubertasnya. Masalah yang sering terjadi adalah siklus mentruasi yang tidak menentu, cenderung lebih emosional pada saat melewati masa pubertas, peningkatan libido saat pubertas dibandingkan anak normal serta remaja putri tunagrahita tidak memahami bahwa mereka sedang berada dalam masa pubertas sehingga ketika mestruasi remaja putri tunagrahita memberitahukan kesemua orang bahkan menunjukkan celana dalam yang penuh darah.

Pada aspek sikap audiens terkait dengan permasalahan kekerasan seksual yang pernah dialami remaja putri tunagrahita. Sebagian besar audiens menyampaikan bahwa remaja putri tunagrahita dahulu pernah mengalami kekerasan seksual berupa pelecehan seksual berupa memegang bagian tubuh yang sensitif dan menggesekgesekkan alat kelamin dan meraba payudara Kejadian tersebut membuat para guru dan kepala sekolah lebih menjaga dan mengawasi tingkah laku remaja putri tunagrahita di sekolah. Menurut Farisa (2013), remaja tunagrahita sebenarnya sama seperti remaja normal yaitu mengalami pubertas akan tetapi libido remaja tunagrahita lebih tinggi dibandingkan dengan remaja normal. Selain libido remaja tunagrahita yang lebih besar dibandingkan remaja normal pada umumnya, permasalahan lain juga pada pemahaman remaja tunagrahita terkait dengan masalah seksualitas yang rendah(11). Penanggulangan kasus kekerasan seksual dapat dilakukan dengan pemberian edukasi yang dikemas dalam bentuk media pembelajaran.Penggunaan media pembelajaran juga dimaksudkan agar penyandang tunagrahita lebih memahami materi edukasi dikarenakan keterbatasan mereka 
dalam memahami tulisan dan huruf sajaAdapun media pembelajaran yang digunakan dalam kegiatan belajar mengajar di SLB bermacam-macam salah satunya adalah media puzzle. Pemilihan media puzzle didasarkan pada kebutuhan SLB-C akan media yang digunakan untuk melatih motorik halus serta merupakan media pembelajaran yang digunakan untuk melatih konsentrasi siwa. Seluruh audiens menyatakan bahwa penggunaan media puzzle dirasa membantu dalam kegiatan pembelajaran. Media puzzle yang dibutuhkan oleh audiens yaitu media puzzle yang mengandung pesan pembelajaran mata pelajaran sesuai dengan kurikulum SLB, mempunyai warna yang cerah, memiliki bentuk yang lucu serta berbahan awet dan tidak berbahaya jika digunakan oleh anak-anak.

Sikap memang merupakan kecenderungan untuk bertindak namun belum tentu nantinya akan terwujud dalam suatu tindakan. Terbentuknya suatu tindakan dipengaruhi oleh beberapa faktor antara lain fasilitas, sarana dan prasaran(7). Berdasarkan hasil wawancara yang dilakukan kepada guru SLB, bahwa para guru memiliki tindakan yang bermacam-macam untuk menangani masalah pubertas dan kekerasan seksual bagi penyandang tunagrahita. Pertama, tindakan yang dilakukan guru SLB untuk mengatasi masalah pubertas adalah dengan memberikan izin untuk libur bagi siswi tunagrahita yang sedang menstruasi, melakukan pengawasan dan pengontrolan di sekolah ketika istirahat terkait dengan pergaulan penyandang tunagrahita dengan sesama teman, pemberian informasi pada saat program khusus bina diri, yaitu program yang dicanangkan untuk membentuk kemampuan penyandang tunagrahita agar mampu hidup mandiri seperti cara memakai baju, cara mandi dan masih banyak lagi. Pada tindakan yang dimaksudkan untuk mengatasi permasalahan kekerasan seksual, audiens biasanya memberikan perlakuan seperti memberikan pengarahan dan pemberian edukasi kepada siswi penyandang tunagrahita terkait masalah kekerasan seksual. Pengarahan yang dilakukan dapat berupa pengarahan dengan menggunakan pendekatan agama.

\section{Desain Strategis}

Setelah pada tahapan analisis audiens, langkah selanjutnya adalah melakukan analisis terhadap desain strategis pengembangan media puzzle. Analisis desain strategis ini melibatkan para ahli yaitu ahli media dan psikolog yang berjumlah empat orang. Merencanakan program-program kesehatan perlu memperhatikan beberapa aspek dan strategi. Strategi ini akan mencakup tujuan komunikasi, segmentasi audiens, pendekatan program, rekomendasi saluran, rencana implementasi(5). Penguatan strategi komunikasi dapat dilakukan dengan penyusunan tujuan perubahan perilaku yang berpengaruh pada pencapaian tujuan program kesehatan. Para ahli menyatakan bahwa tujuan pembuatan media harus disesuaikan dengan materi yang didalamnya. Sukaningtyas and Sa'ud (2017) juga menyatakan bahwa visi, misi dan tujuan merupakan sesuatu yang saling terkait walaupun masing-masing memiliki definisi yang berbeda(12). Sehingga tujuan pembuatan media puzzle dirumuskan menjadi dua bagian sesuai dengan isi materi yang terkandung didalamnya yaitu mengajarkan remaja putri penyandang tunagrahita untuk mengenali masa pubertas serta mengajarkan remaja putri penyandang tunagrahita bagian tubuh yang tidak boleh disentuh orang lain selain orang tua dan cara menolaknya.Setelah menentukan tujuan, tahapan selanjutnya yang dilakukan adalah mengembangkan pendekatan dan posisi program. Pengembangan pendekatan dan posisi program dilakukan dengan cara menentukan judul yang tepat yang menggambarkan isi media nantinya serta menentukan tag line yang sesuai supaya mudah diingat oleh sasaran dan menjadi cirri khas produk. Para ahli menyatakan bahwa judul dan tagline yang diambil harus sesuai dengan tujuan dan materi yang terdapat didalam media. Bahkan salah satu ahli media menambahkan bahwa judul dan tagline yang baik adalah judul dan tagline yang sederhana dan menarik, sehingga hasil akhir judul media Puzzle yaitu Pendidikan Seksual Bagi Remaja Putri Tunagrahita yang disingkat menjadi "Kanal Rata" kemudian untuk tagline menjadi ayo kenali tubuhmu. Abdurrahman (2016) menyatakan bahwa pemilihan judul harusnya tidak bersifat multi tafsir sehingga pembaca nantinya akan mengerti apa yang akan dibahas didalamnya(13). Pada tahapan berikutnya dalam desain strategis adalah menentukan saluran komunikasi yang paling tepat untuk menjangkau sasaran sangat penting sebelum memutuskan materi yang akan di buat. 
Saluran media merupakan program tertentu yang digunakan untuk mengenalkan media puzzle, dalam penelitian ini saluran yang dipilih adalah program khusus yang diberi nama bina diri. Seluruh ahli baik ahli media maupun psikolog menyatakan bahwa saluran media puzzle yang dipilih oleh peneliti sudah sesuai yaitu program bina diri. Bina diri merupakan kurikulum khusus untuk siswa penyandang disabilitas yang bertujuan untuk mengajarkan siswa agar dapat hidup mandiri. Contoh aspek yang diajarkan dalam program ini adalah cara mandi, cara memakai baju, cara menggunakan pembalut, cara merias diri dan masih banyak lagi. Tjasmini (2014 ) juga menyatakan bahwa memang remaja putri tunagrahita membutuhkan satu program pembelajaran yang akan mengatasi kebutuhan akan pendidikan seksual dan organ reproduksi, dan program tersebut adalah bina diri(14).

Langkah terakhir dalam desain strategis adalah mengembangkan jadwal. Mengembangkan jadwal dalam bentuk timeline kegiatan untuk menciptakan kinerja yang terorganisir dan terstruktur, dapat menjamin kegiatan implementasi tetap berjalan sesuai dengan jalurnya serta menentukan peran dan penanggungjawab kegiatan dalam program yang akan dijalankan(5). Seluruh ahli baik ahli media maupun psikolog menyatakan bahwa rencana implementasi sudah sesuai yaitu pemberian media puzzle selama 3 bulan. Hal ini dikarenakan pada penyandang tunagrahita membutuhka pengajaran yang harus diulang-ulang sehingga membutuhkan waktu yang cukup lama dibandingkan anak normal. Menurut ahli psikolog, pemberian media puzzle bisa dilakukan dengan memberikan materi pengenalan bagian tubuh yang tidak boleh disentuh terlebih dahulu hingga siswi SLB-C paham, baru kemudian materi tentang pubertas. Hal tersebut karena kemampuan untuk mencapai keberhasilan belajar secara akurat dan tuntas adalah dengan berlatih dan melakukan praktek secara berulang-ulang, yang diterapkan pada berbagai subjek yang akan diukur kemampuan merawat diri sendiri(15).

\section{KESIMPULAN DAN SARAN}

Berdasarkan hasil analisis dalam pembahasan maka dapat ditarik kesimpulan Hasil analisis audiens dengan melihat pengetahuan, sikap, tindakan informan terkait masalah pubertas dan kekerasan seksual serta kebutuhan media puzzle didapatkan hasil sebagian besar audiens sudah mengetahui terkait masalah tersebut namun belum mendalami sehingga diperlukan pendalaman materi terkait pubertas dan kekerasan seksual. Pada aspek sikap, sebagian besar audiens menyatakan sepakat bahwa remaja putri tunagrahita mengalami masalah terkait dengan pubertas dan kekerasan seksual. Pada aspek tindakan audienssebagai upaya mengatasi permasalahan pubertas dan kekerasan seksual, seluruh informan memiliki berbagai macam dan cara paling banyak dilakukan adalah memberikan pemahaman dan pengarahan kepada siswa SLB. Selain itu, seluruh audiens sepakat bahwa penggunaan media puzzle sangat membantu mereka dalam memberikan materi saat proses selajar mengajar. Pada aspek kebutuhan akan media puzzle, seluruh audiens menyatakan bahwa media puzzle yang dibutuhkan di SLB adalah media puzzle yang mengandung pesan pembelajaran sesuai dengan kurikulum yang dikeluarkan oleh Dinas Pendidikan.

Hasil analisis desain strategis oleh para ahli didapatkan hasil bahwa dalam pembuatan media puzzle, perancangan tujuan harus sesuai dengan materi yang terkandung di dalam media puzzle. Selanjutnya dalam perancangan pendekatan dan posisi program berupa judul dan tagline pada media puzzle harus merujuk pada tujuan dan isi, selain itu yang perlu diperhatikan adalah penggunaan bahasa yang mudah dimengerti oleh remaja putri tunagrahita. Proses selanjutnya yaitu penetapan saluran program yaitu bina diri sudah sesuai untuk digunakan sebagai wadah untuk menyampaikan materi dengan media puzzle. Terakhir adalah penyusunan timeline kegiatan perubahan perilaku yang dihasilkan dengan media puzzle yaitu tiga bulan dengan pemakaian media puzzle secara bergantian dimulai dengan puzzle pengenalan bagian tubuh kemudian pengenalan pubertas. 


\section{REFERENSI :}

1. Rahmasari P. Peran Guru Dalam Pendidikan Kesehatan Reproduksi Bagi Siswi Remaja Tunagrahita Ringan Di Sekolah Luar Biasa (SLB) Sleman Yogyakarta [Internet] [Thesis]. UNS (Sebelas Maret University); 2016 [Dikutip 1 Oktober 2018].

2. Goli S, Noroozi M, Salehi M. A Comprehensive Sexual Health Care Program For Educable Intellectually Disabled Adolescent Girls: Protocol For A Mixed Methods Study. Reprod Health. 22 Agustus 2018;15(1):141.

3. Mais A. Media Pembelajaran Anak Berkebutuhan Khusus (ABK): Buku Referensi Untuk Guru, Mahasiswa Dan Umum. Pustaka Abadi; 2016. 202 Hlm.

4. Paramarta D. Pola Asuh Ibu Terhadap Kebersihan Pribadi Organ Reproduksi Pada Penyandang Tunagrahita Yang Sudah Mengalami Menstruasi (Studi Kualitatif Siswi SLB-C TPA Jalan Jawa No. 57 Kecamatan Sumbersari Kabupaten Jember). 27 Juli 2018 [Dikutip 5 Oktober 2018];

5. The Johns Hompkins University. The P Processtm Five Steps To Strategic Communication. November 2013;40.

6. Hakim TL. Kelayakan Kit Fasilitator Sebagai Media Komunikasi Informasi Dan Edukasi (Kie) Dalam Upaya Pencegahan Terhadap Pedofilia Bagi Siswa Sekolah Dasar (Sd). 8 November 2018 [Dikutip 11 November 2018];

7. Notoatmodjo S. Ilmu Perilaku Kesehatan. Cetakan Ke 2. Jakarta: Rineka Cipta; 2014. $174 \mathrm{Hlm}$.

8. Tarwoto, Dkk. Kesehatan Remaja Problem Dan Solusinya. Jakarta: Salemba Medika; 2010. $152 \mathrm{Hlm}$.

9. Verawaty SN, Rahayu L. Merawat Dan Menjaga Kesehatan Seksual Wanita. Cetakan 1. Bandung: PT Grafindo Media Pratama; 2012. 344 Hlm.

10. Tim Admin ASI-MPASI (SAM) TAGS. Superbook For Supermom: Bagian 8 [Internet]. Fmedia; 2015. $48 \mathrm{Hlm}$.

11. Farisa TD. Faktor-Faktor Penyebab Perilaku Seksual Menyimpang Pada Remaja Tunagrahita SLB N Semarang (Case Study) [Internet]. [Semarang]: Universitas Negeri Semarang; 2013.

12. Sukaningtyas D, Sa'ud US. Pengembangan Kapasitas Manajemen Sekolah Dalam Membangun Pemahaman Visi Dan Misi. J Ilmu Pendidik [Internet]. 2017;22(2).

13. Abdurrahman. Spiritual Writing: Menulis Dengan Iman [Internet]. Ebookuid; 2016. 136 Hlm.

14. Tjasmini M. Pembelajaran Bina Diri Dalam Membantu Pemahaman Kesehatan Reproduksi Pada Remaja Putri Tunagrahita. Edutech. 12 Agustus 2014;13(2):204-10.

15. Adnyani Dnn, Prof. Dr. Ni Ketut Suarni Ms, Dr. I Nyoman Jampel Mp. Pengaruh Metode Drill Terhadap Motivasi Belajar Dan Kemampuan Merawat Diri Sendiri Bagi Anak Tunagrahita Pada Pelajaran Bina Diri Siswa Kelas I Slb.C1 Negeri Denpasar Tahun PELAJARAN 2014/2015. J Penelit Dan Eval Pendidik Indones [Internet]. 4 Agustus 2015 [Dikutip 5 September 2019]; 